\title{
Disseminated peritoneal leiomyomatosis: a rare entity with diagnostic conundrum
}

\author{
Pradip Kumar Saha ${ }^{1 *}$, Lakhbir Kaur Dhaliwal ${ }^{1}$, Shalini Gainder ${ }^{1}$, Rashmi Bagga $^{1}$, \\ Bharti Joshi ${ }^{1}$, Shubas Chandra Saha ${ }^{1}$, Rajesh Gupta ${ }^{2}$
}

\begin{abstract}
${ }^{1}$ Department of Obstetrics and Gynecology ${ }^{2}$ Department of Surgery, Postgraduate Institute of Medical Education and Research Chandigarh, Pin 160012, India
\end{abstract}

Received: 26 June 2015

Accepted: 09 July 2015

*Correspondence:

Dr. Pradip Kumar Saha,

E-mail: pradiplekha@yahoo.co.in

Copyright: (C) the author(s), publisher and licensee Medip Academy. This is an open-access article distributed under the terms of the Creative Commons Attribution Non-Commercial License, which permits unrestricted non-commercial use, distribution, and reproduction in any medium, provided the original work is properly cited.

\begin{abstract}
Disseminated peritoneal leiomyomatosis (DPL) is a rare, usually benign disease primarily affecting premenopausal women. It is signalized by multiple smooth muscle nodules which grossly or radiologically may simulate peritoneal carcinomatosis or disseminated intraabdominal malignancies. A case study of 45 year female who presented with DPL after 8 years of hysterectomy is reported here.
\end{abstract}

Keywords: Peritoneal leiomyomatosis, Diagnostic conundrum

\section{CASE HISTORY}

A 45 year multiparous lady presented with complaint of vague pain abdomen and heaviness for last 6 months. There was no complaint of mass abdomen, bleeding per vagina, bowel or bladder disturbance and dyspepsia. There was no history of fever, loss of appetite or weakness although she revealed history of weight loss for past 4 months. She had hysterectomy done in 2004 for symptomatic fibroids (menorrhagia) and related surgery report stated multiple intramural and subserosal myomas. There was history of hysterectomy in mother and sister in view of fibroid uterus. In her obstetrics history she had two term vaginal delivery

Her general physical examination was fair with no evidence of pallor, edema, jaundice and lymphadenopathy. Her vitals were normal and chest and cardiovascular examination did not revealed any abnormality. Per abdominal examinations revealed transverse scar in lower part with no evidence of organomegaly or abdominopelvic mass.
Local and per vaginal examination revealed no abnormality. Ultrasonography showed right adnexal masses of $(6 \times 4 \mathrm{~cm})$ with mixed echogenecity and left adnexal mass of $(3.2 \times 2.8) \mathrm{cm}$. On CT scan examination there was right adnexal mass $(6 \times 7 \mathrm{~cm})$, nodular, variegated stuck to right ovary and left ovary measuring $3.2 \times 2.8 \mathrm{~cm}$ with a cyst of $2 \mathrm{~cm}$ with low level echogenecity. Fine Needle Aspiration Cytology (FNAC) from right mass suggested scanty cellularity with benign mesothelial cells .Her hematological and biochemical examinations did not reveal any abnormality and CA-125 was 19.9 units $/ \mathrm{ml}$.

Patient was taken for exploratory laparotomy with midline vertical incision. Intraoperatively multiple nodules were seen of varying size over the mesentery of sigmoid colon, rectum, pelvic peritoneum, surface of terminal ileum of max size $2 \mathrm{~cm}$. Bilateral ovaries were grossly normal with no ascites [Figure 1]. Uterus was absent due to post hysterectomy status. Nodules resected from mesentery \& sent for frozen section. Microscopic examination reported as benign leiomyoma. Debulking of 
nodules was done from mesentery and surface of ileum. Two feet of ileal resection [Figure 2] from iliocecal junction and end to end anastomosis was done. Bilateral oophrectomy was also performed.

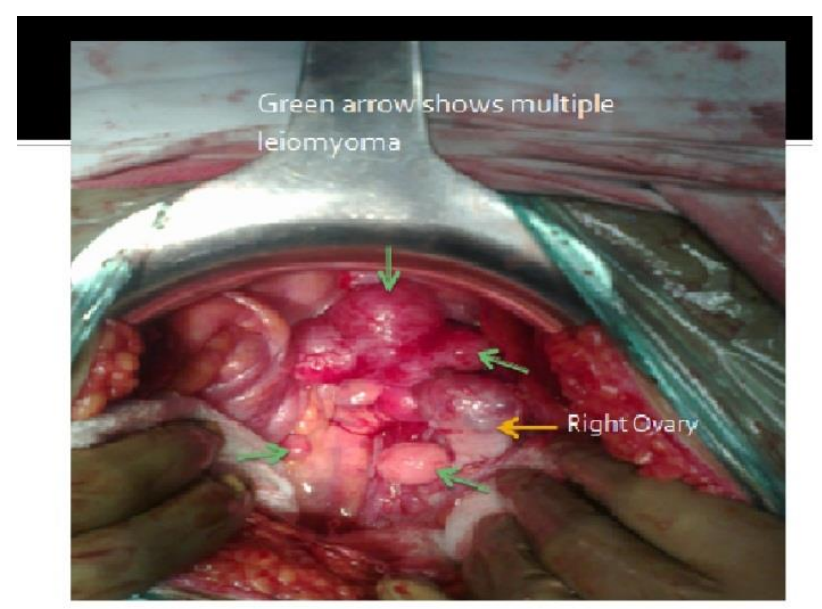

Figure 1: Multiple leiomyomatosis.

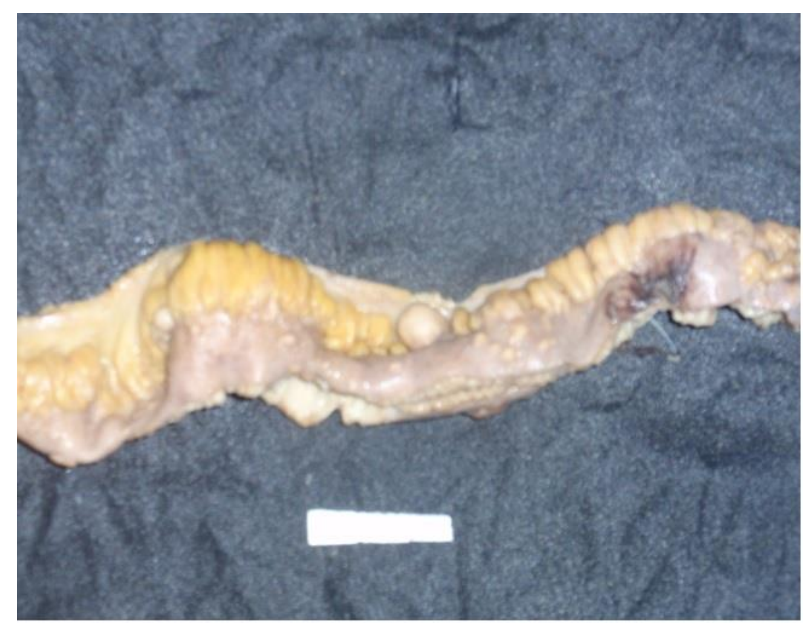

Figure 2: Removed part of the intestine involved by leiomyomatosis.

Final histopathology report from multiple sites also showed similar pathology. Patient discharged on $10^{\text {th }}$ post-operative day. Patient is on follow up since 2 years without any complaint.

\section{DISCUSSION}

Disseminated peritoneal leiomyomatosis (DPL), a rare disease of mainly reproductive age group is characterized by multiple smooth muscle nodules which morphologically resemble peritoneal carcinomatosis or disseminated intraabdominal malignancies. ${ }^{1}$ The estimated prevalence of DPL is cited as $<1 / 10,00,000$ with fewer than 150 cases reported in literature till date. Etiology of the DPL is still unclear since first case described by Wilson and Peale in $1952 .{ }^{2}$ Some advocates describe it as a multifactorial disease with hormonal or genetic elements resulting in metaplasia of submesothelial mesenchymal cells or could be induced after morcellation of myoma during laparoscopy. ${ }^{3-5}$ The frequent association of this condition with pregnancy, prolonged use of oral contraceptives, uterine fibroid and existence of estrogen and progesterone receptor within DPL may justify its hormonal dependence. ${ }^{1,6,7}$

Most of the patients of DPL are usually asymptomatic and diagnosed incidentally during caesarean or laparotomy. Disseminated peritoneal leiomyomatosis may pose diagnostic and management challenges for surgeon and pathologist because of spectrum of appearances. Multiple, hard solid nodules may extensively involve the surface of peritoneum, uterine fundus, ovaries, colon mesentery, omentum and gut and overall picture can be misguiding, confusing and may overlap with appearance of disseminated abdominal malignancies or metastatic leimyosarcoma. Clinical features like absence of omental caking or ascites and quick microscopic review of the nodule are the best tools in making accurate diagnosis and appropriate management. ${ }^{4-8}$

Disseminated peritoneal leiomyomatosis, mostly asymptomatic or with confusing and vague peritoneal symptoms, can yield a dramatic clinical picture when discovered, as in our case or it can be diagnosed while the patient is explored for some other reason. ${ }^{8}$ Most of the time it diagnosed years after myomectomy or hysterectomy. ${ }^{9,10}$ Absence of characteristic clinical features and misleading gross appearance makes accurate diagnosis possible only by means of microscopic examination as in index case. Sometimes imaging modalities may be confusing, inconclusive as they may suggest the possibility of malignant condition or the tiny peritoneal nodules may be below the resolution of all radiologic techniques. Our patient had hysterectomy done for fibroid uterus 8 years back however ovaries were left. Her nonspecific clinical symptoms of abdominal discomfort and heaviness with radiological findings of bilateral solid adnexal masses evoked suspicion of malignancy and decision of laparotomy was taken. Intraoperative findings of grossly normal ovaries and fallopian tubes, presence of multiple, small, multicolored nodules with absence of ascites although assured us that metastatic ovarian cancer is unlikely as it would produce white gray friable nodules but in order to decide the extent of surgery and to rule out other disseminated intraabdominal malignancies frozen section was considered. The analysis of our case reflects that patient had tendency for leiomyomas as she had hysterectomy for fibroids and her source of endogenous gonadal hormones (ovaries) were in situ. Our consideration is in agreement with hypothesis of hormonal dependent nature of the tumor and its relationship to the fibroids. ${ }^{5}$

Disseminated peritoneal leiomyomatosis although a disease of reproductive age group, very few cases has been described in postmenopausal women. ${ }^{11}$ Risk of malignant degeneration is $10 \%$ in DPL as indicated from recent studies which is higher than in solitary leiomyoma. $^{12}$ 
No standard guidelines or recommendations exist for the management of the DPL and treatment needs individualization taking into consideration the patient age, desirous for conception and symptomatology. ${ }^{13}$ The advocated management of DPL is total abdominal hysterectomy and bilateral salpingoophrectomy along with resection of myomatous nodules (debulking) depending upon the extent of the disease .Although this is not potentially curative but can be used to treat evidential lesions. Medical castration using gonadotropin releasing hormone/danazol has been tried in cases of recurrence or progression but with poor results. In post menopausal woman aromatase inhibitor (anastarzole) has been used with success to treat non resectable tumor. ${ }^{14}$

Prognosis of DPL is usually fare however disease can be fatal in some cases presenting as unresectable or metastatic. Post-operative surveillance on annual basis with imaging for at least 3 years is suggested because of reported recurrence interval of 7 months to 8years. ${ }^{14,15}$ Our patient is under follow up since two yeasr and she has remained uneventful.

\section{CONCLUSION}

Because of rarity and possible unfamiliarity to this condition, potential misdiagnosis of disseminated peritoneal leiomyomatosis with disseminated malignancy has been made and on many occasions extensive dissection had led to the increased morbidity and mortality. So careful consideration and high index of suspicion is required for proper management of such cases.

\section{Funding: No funding sources}

Conflict of interest: None declared

Ethical approval: Not required

\section{REFERENCES}

1. Paul PG, Naik S. Disseminated leiomyomatosis peritonei. Incidental finding in laparoscopy: a case report. Surg Laparosc Endosc Percutan Tech. 2010;20:e123-e124.

2. Fasih N, Prasad Shanbhogue AK, Macdonald DB, Fraser-Hill MA, Papadatos D, Kielar AZ, Doherty GP, Walsh C, McInnes M, Atri M. Leiomyomas beyond the uterus: unusual locations, rare manifestations. Radiographics. 2008;28:1931-48.

3. Al-Talib A, Tulandi T. Pathophysiology and Possible Iatrogenic Cause of Leiomyomatosis Peritonealis Disseminata. Gynecol Obstet Invest. 2010;69:23944.

4. Sobiczewski P, Bidziński M, Radziszewski J, Panek G, Olszewski W, Tacikowska M, et al. Disseminated peritoneal leiomyomatosis -case report and literature review. Ginekol Pol. 2004;75:215-20.

5. Drake A, Dhundee J, Buckley $\mathrm{CH}$, Woolas R. Disseminated leiomyomatosis peritonealis in association with oestrogen-secreting ovarian fibrothecoma. BJOG. 2001;108:661-4.

6. Ramesh L, Edozien L. Not all disseminated intraabdominal lesions are malignant: A case of leiomyomatosis peritonealis disseminata. J Obstet Gynaecol. 2005;25:409.

7. Singh G, Gordon-Harris L, Frazer G.B., Walker S. "Case report: leiomyomatosis peritonealis disseminata - diagnosis by sonography," Indian Journal of Radiology and Imaging. 2002;12(4):497500.

8. Surmacki P,Sporny S, Tosiak A, Lasota J. Disseminated peritoneal leiomyomatosis coexisting with leiomyoma of the uterine body. Arch Gynecol Obstet. 2006;273:301-3.

9. Miyake T, Enomoto T, Ueda Y, Ikuma K, Morii E, Matsuzaki S, et al. A case of disseminated peritoneal leiomyomatosis developing after laparoscopeassisted myomectomy :Gynecol Obstet Invest. 2009;67(2):96-102.

10. Sinha R, Sundaram M, Mahajan C, Sambhus A Multiple leiomyomas after laparoscopic hysterectomy: report of two cases.:J Minim Invasive Gynecol. 2007;14(1):123-7.

11. Abulafia O, Angel C, Sherer DM, Fultz PJ, Bonfiglio TA, DuBeshter B . Computed tomography of leiomyomatosis peritonealis disseminata with malignant transformation. Am J Obstet Gynecol. 1993;169:52-4.

12. Bekkers RL, Willemsen WN, Schijf CP, Massuger LF, Bulten J, Merkus JM, .Leiomyomatosis peritonealis disseminata: does malignant transformation occur? A literature review. Gynecol Oncol. 1999;75:158-63.

13. Bhattacharya S, Pati S, Naskar A, Dey S. An Atypical Case of Pelvic Leiomyomatosis Peritonealis Disseminata. Online J Health Allied Scs. 2010;9(2):12.

14. Raspagliesi F, Quattrone P, Grosso G, Cobellis L, Di Re E. Malignant degeneration in leiomyomatosis peritonealis disseminata. Gynecol Oncol. 1996;61:272-4.

15. Jeyarajah S, Chow A, Lloyd J, Zacharakis E, Purkayastha S, Paris Tekkis P Follow-up in patients with disseminated peritoneal leiomyomatosis: a report of an unusual, high-risk case. BMJ Case Rep. 2009; 2009.

Cite this article as: Saha PK, Dhaliwal LK, Gainder S, Bagga R, Joshi B, Saha SC, Gupta R.

Disseminated peritoneal leiomyomatosis: a rare entity with diagnostic conundrum. Int J Reprod Contracept Obstet Gynecol 2015;4:1194-6. 